\title{
Self-rated worry is associated with hospital admission in out-of-hours telephone triage - a prospective cohort study
}

Hejdi Gamst-Jensen ${ }^{1,2^{*}}$ (D), Erika Frischknecht Christensen ${ }^{3,4}$, Freddy Lippert ${ }^{1}$, Fredrik Folke ${ }^{1,5}$, Ingrid Egerod ${ }^{6}$, Linda Huibers ${ }^{7}$, Mikkel Brabrand ${ }^{8,9}$, Janne Schurmann Tolstrup ${ }^{10}$ and Lau Caspar Thygesen ${ }^{10}$

\begin{abstract}
Objective: Telephone triage manages patient flow in acute care, but a lack of visual cues and vague descriptions of symptoms challenges clinical decision making. We aim to investigate the association between the caller's subjective perception of illness severity expressed as "degree-of-worry" (DOW) and hospital admissions within $48 \mathrm{~h}$.

Design and setting: A prospective cohort study was performed from January 24th to February 9th, 2017 at the Medical Helpline 1813 (MH1813) in Copenhagen, Denmark. The MH1813 is a primary care out-of-hours service.

Participants: Of 38,787 calls received at the MH1813, 11,338 met the inclusion criteria (caller being patient or close friend/relative and agreement to participate). Participants rated their DOW on a 5-point scale ( $1=$ minimum worry, $5=$ maximum worry) before talking to a call handler.

Main outcome measure: Information on hospitalization within $48 \mathrm{~h}$ after the call, was obtained from the Danish National Patient Register. The association was assessed using logistic regression in three models: 1) crude, 2) ageand-gender adjusted and 3) age, gender, co-morbidity, reason for calling and caller status adjusted.

Results: A total of 581 participants (5.1\%) were admitted to the hospital, of whom 170 (11.3\%) presented with a maximum DOW, with a crude odds ratio (OR) for hospitalization of 6.1 (95\% confidence interval (Cl) 3.9 to 9.6) compared to minimum DOW. Estimates showed dose-response relationship between DOW and hospitalization. In the fully adjusted model, the ORs decreased to $3.1(95 \% \mathrm{Cl} 2.0$ to 5.0$)$ for $\mathrm{DOW}=5,3.2$ (2.0 to 5.0) for DOW = 4, 1.6 (1.0 to 2.6) for DOW $=3$ and 0.8 (0.5 to 1.4) for DOW $=2$ compared to minimum DOW.

Conclusion: Patients' self-assessment of illness severity as DOW was associated with subsequent hospital admission. Further, it may be beneficial in supporting clinical decision making in telephone triage. Finally, it might be useful as a measure to facilitate patient participation in the triage process.
\end{abstract}

Keywords: Decision support systems, Emergency medicine, Telephone hotlines, Triage, Patient-centered care, Decision making, Help-seeking behavior

\footnotetext{
* Correspondence: Hejdi.Gamst-Jensen@regionh.dk

${ }^{1}$ Emergency Medical Services Copenhagen, Copenhagen University, Copenhagen, Denmark

${ }^{2}$ Clinical Research Centre, Amager and Hvidovre Hospital, University of Copenhagen, Copenhagen, Denmark

Full list of author information is available at the end of the article
}

(c) The Author(s). 2020 Open Access This article is licensed under a Creative Commons Attribution 4.0 International License, which permits use, sharing, adaptation, distribution and reproduction in any medium or format, as long as you give appropriate credit to the original author(s) and the source, provide a link to the Creative Commons licence, and indicate if changes were made. The images or other third party material in this article are included in the article's Creative Commons licence, unless indicated otherwise in a credit line to the material. If material is not included in the article's Creative Commons licence and your intended use is not permitted by statutory regulation or exceeds the permitted use, you will need to obtain permission directly from the copyright holder. To view a copy of this licence, visit http://creativecommons.org/licenses/by/4.0/. The Creative Commons Public Domain Dedication waiver (http://creativecommons.org/publicdomain/zero/1.0/) applies to the data made available in this article, unless otherwise stated in a credit line to the data. 


\section{Background}

Telephone triage is widely used in acute care and emergency medicine. It encompasses both emergency calls and non-life-threatening acute situations. Telephone triage is used to determine urgency and the type of health care needed and also to manage patient flow, but it is a difficult task due to the lack of visual cues and the innate gate-keeping role of the service [1-3]. Most calls to medical helplines are for non-life-threatening conditions, often presented with an array of symptoms that might not fit textbook descriptions $[4,5]$. Nevertheless, conditions with a potentially severe outcome are also part of the incoming calls and it is crucial to identify these calls. Triage tools are recommended to aid health care professionals' decision making [6], but these tools generally perform well only in the low and high levels of urgency, but less so in the middle triage categories [6, 7], moreover, they are criticized for not incorporating the patient's context and perception nearly enough [8,9]. In a Danish study from 2019 based on 200 calls to a medical helpline, researchers found that less than $2 \%$ of the callers were invited to express their emotional state [10]. Therefore, a need exists for a tool that systematically incorporates the patient's perception of the situation and symptoms in telephone triage.

People tend to form their own perception of the situation in case of an illness or injury [11]. This is exemplified by the Common Sense Model showing five cognitive dimensions of illness representation: identity the label the person assigns to the symptoms; consequences - the expected outcome of the symptoms; cause - idea of what caused the illness; timeline - expected duration of the illness, and perceived cure or control over the disease [12]. Moreover, three emotional representations (i.e. fear, anger and distress) incorporate the negative reactions to illness $[11,13]$. Emotional representations, such as concern, have been found to predict worse illness outcome [14]. Worry, or concern, is the most frequent motivator for seeking help out-of-hours, and studies of malpractice claims in telephone triage show, that a failure to listen to the patient and the use of closed questions compromise patient safety [15-17]. The newly developed degree-of-worry scale (DOW), which was tested on 180 callers at a medical helpline, showed promising results to aid patient centered communication, in the regard that patients volunteered more medical-and-context-related information [18]. Moreover, self-rated health has been recognized as a valid predictor of all-cause mortality for decades. People with poor self-rated health status have approximately twice as high all-cause mortality than those reporting good health [19-21]. Self-rated health is an inclusive, usually five-point rating, that is thought to provide individual but contextual relevant information on bodily conditions, sensations, emotions and feelings $[22,23]$. The DOW scale provides the call handler with the callers' perception of illness severity measured as DOW. Considering that people can predict mortality through self-rated health, it might be valid to include DOW as an addition to current triage tools.

We aimed to investigate the association between the caller's subjective perception of illness severity expressed as "degree-of-worry" (DOW) and the likelihood of being admitted to the hospital within $48 \mathrm{~h}$. We used hospital admission within $48 \mathrm{~h}$ following a call to a medical helpline as a proxy of illness severity [6].

\section{Methods}

Study design

A prospective cohort study that combines the callers self-reported worry (DOW) with data from nationwide registers to evaluate the association with hospital admission [24].

\section{Setting}

The Capital Region of Denmark covers an area of 2568 $\mathrm{km}^{2}$ with a population of 1.8 million people [25]. The acute care system within the Capital Region of Denmark, Copenhagen, offers two different access points (telephone numbers) to the Emergency Medical Service: 11-2 for the presumed life-threatening injuries and illnesses and the medical helpline 1813 (MH1813) for non-life-threatening acute illness or injury. The MH1813 handles approximately 1 million calls per year, is an integrated part of the Emergency Medical Services and has incorporated the Out-Of-Hours $(\mathrm{OOH})$ services. All acute non-life-threatening contacts to the health care system within the region are pre-assessed by a registered nurse or physician, who triage the caller to either advice and self-care, own general practitioner (GP), clinic consultation at an emergency department, home visit, hospital admission, or dispatch of an ambulance. Approximately $40 \%$ are triaged to either self-care or their own GP. Triage is guided by a criterion-based electronic triage tool, which is a detailed instruction based on symptoms and symptom intensity that guides the call handler in questions and responses. The triage tool used at the medical helpline is developed locally and has not been validated. The population for this study consisted of callers to the MH1813 for perceived non-lifethreatening illnesses/injuries.

\section{Participants}

The data collection was conducted by telephone from January 24th to February 9th, 2017 and linked to the patient's personal identification number (PIN) making 
linkage with registers possible. We included all patients calling during the data collection period, in case of several contacts we only used the first call. The choice of using the first call was based on the clinical perspective of possible under-triage. Exclusion criteria were refusal to participate, call by bystander (not relative or close friend), missing information on DOW and calls from persons without permanent Danish residency since they cannot be followed in registers. This study was planned and performed on the same study cohort used for a randomized controlled trial (RCT) [26]. The aim of the RCT was to investigate the effect on triage of the call handlers' awareness of the callers DOW, and found no difference in proportion of callers triaged to a face-to-face consultation between intervention group and control group. The lack of effect on DOW on triage response was likely due to the fact that the call handlers did not pay attention to the displayed DOW [26].

\section{Data sources and variables}

Data was derived from four different sources.

\section{Registration at the $\mathrm{MH} 1813$}

The internal data-registration has an incorporated triage tool where contact and patient related variables are registered. We collected information on reason for calling and triage response (see below).

The Danish Civil Registration System includes all permanent residents in Denmark [27]. Information on date of birth, gender, migration and mortality was obtained from the register.

Danish National Patient Register is a nationwide register that holds information on all in-hospital contacts including diagnoses and procedures since 1977 and emergency room and out-patient contacts since 1995. Information on date and time for hospital admission along with discharge and primary diagnosis were collected [28].

\section{Survey data}

Data was collected electronically using a message on the telephone while callers were waiting in line. Callers who agreed to participate were asked to state if they were the patient themselves or a relative/friend. Hereafter, callers were asked to rate their DOW by answering the question: "How worried would you say you are about the situation you are calling about on a scale from 1 to 5 , where 1 is minimal worry and 5 is maximum worry?"

\section{Covariates}

Triage response was categorized into three groups: Telephone consultation (advice of self-care, referral to own
GP), face-to-face consultation (primary care health professional, consultation at emergency department, direct hospital admission, and ambulance dispatch), and other (e.g. prescription of medicine). Age was categorized (0-5, 6-17, 18-65, 66+ years). Co-morbidity was estimated by the Charlson comorbidity index $[29,30]$ including diagnoses for all hospital contacts up to 10 years before the call, and then grouped into no comorbidity (score 0 ), low co-morbidity (score 1) and moderate or high co-morbidity (score $2+$ ). Reason for calling was categorized as somatic illness, somatic injury, psychiatric illness and other. Caller status was divided into the patient themselves or relative/friend. The variables of age and co-morbidity were collected as continuous data, which resulted in violation of goodness of fit. Therefore, the categorized variables were used for adjusting the models.

\section{Outcome measures}

The outcome measure was hospital admission defined as hospital stay $\geq 24 \mathrm{~h}$ starting within $48 \mathrm{~h}$ after the call to the medical helpline.

\section{Statistical methods}

The association between the five-point DOW and hospital admission was evaluated with three logistic regression models: A crude model, an age-gender adjusted model and a fully adjusted model including age, gender, co-morbidity, reason for calling and caller status. The goodness of fit for the regression models was assessed by the Hosmer and Lemenshow test, which did not indicate violation of model fit for the crude analysis $(p=1.00)$, the age-and gender adjusted analysis $(p=0.58)$ and the fully-adjusted model $(p=0.15))$ Odds ratios (ORs) were estimated with DOW 1 as reference.

Results were reported as ORs with the corresponding 95\% confidence intervals (95\%CI). A significance level below 0.05 was considered significant. Data was analyzed using SAS enterprise 7.12.

A sensitivity analysis was carried out, including the last call in the crude model rather than the first call. Nonresponse bias was assessed with information on gender, age, reason for contact and triage response for all calls during the data collection period compared to the study population. Data from the latter was collected from administrative data (Appendix).

\section{Results}

\section{Population}

A total of 38,787 patients made a call to the MH1813 during the data collection period (Fig. 1). Of these, 12, 902 (33\%) agreed to participate. As 699 calls were made by a person not being the patient or a relative/friend of 


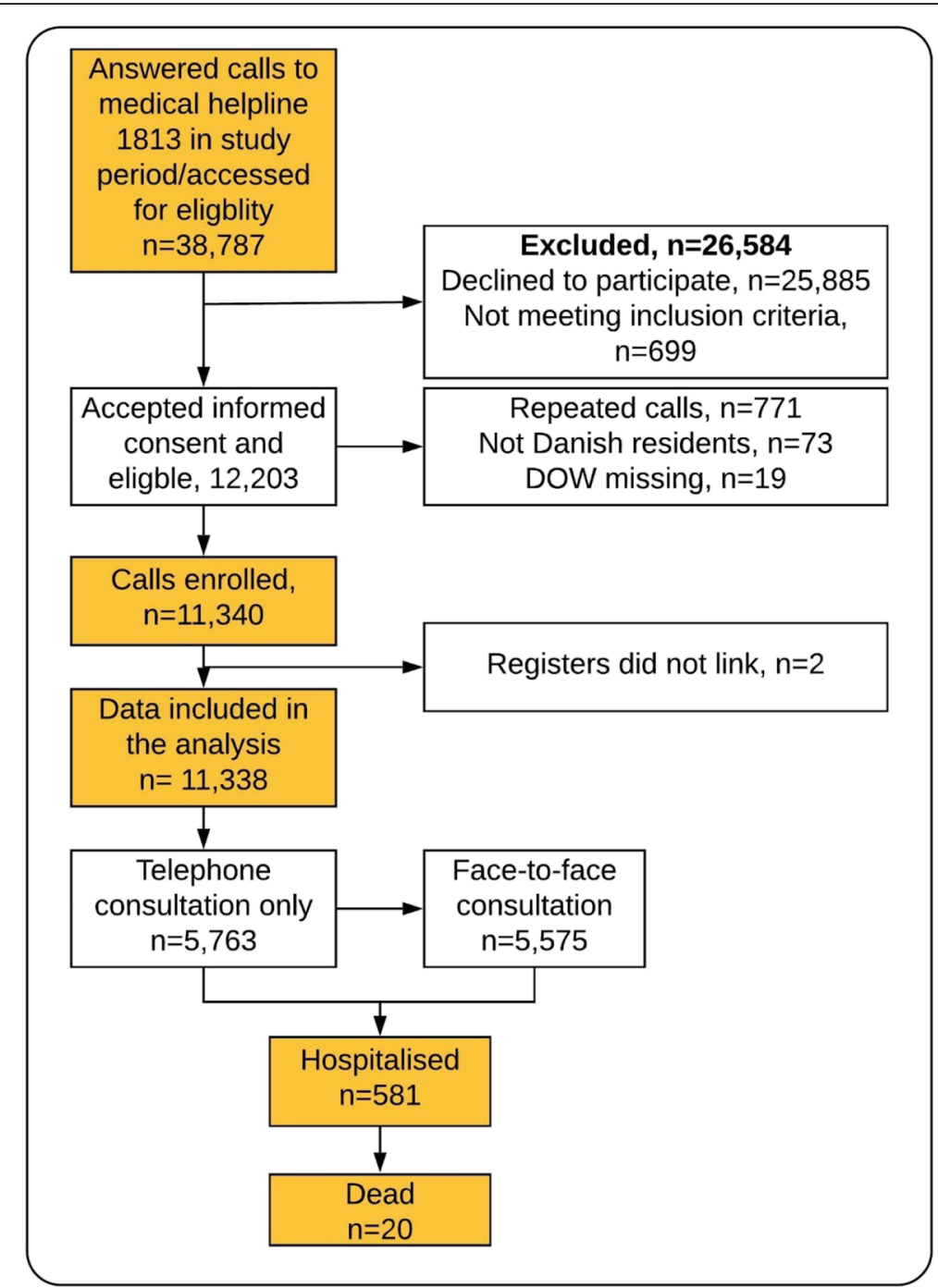

Fig. 1 Flowchart of included calls. Triage outcome (consultation vs. face-to-face consultation) is as registered in the Danish National Patient Register - the absence of an entry in the Danish National Patient Register indicates a contact that has received telephone consultation only

the patient, 12,203 calls were eligible for the study. However, 19 calls were excluded due to missing DOW (the phone was answered by a call handler before the questionnaire was ended), 73 calls were from persons without permanent residency and 771 calls were repeated calls, where only the first call was included. Two calls could not be linked to the National Patient Register. Thus, 11,338 calls were included in the final analysis.

Half of the participants were female (54\%) and the median age was 30.5 years (Table 1). A total of 1073 callers $(9 \%)$ reported minimal worry $(\mathrm{DOW}=1)$ and $2396(21 \%)$ a $\mathrm{DOW}=2$, while the largest group reported $\mathrm{DOW}=3 \quad(36 \%)$. A total of $2283 \quad(20 \%)$ reported a DOW $=4$ and 1500 (13\%) were maximum worried $(\mathrm{DOW}=5)$.

The main reason for contact was somatic illness/injury (72\%), whereas psychiatric illness contributed with less than $1,4 \%$ were miscellaneous questions e.g. answers to blood tests, other guidance, or case summary after home visits and $24 \%$ had a missing reason for calling. A total of $49.2 \%(n=5575)$ of the calls ended with an acute care contact registered in NPR (hospital face-to-face consultation).

\section{Hospital admission}

Of 11,338 telephone contacts, 581 (5.2\%) persons were admitted to the hospital (Fig. 1) within $48 \mathrm{~h}$ of calling. 
Table 1 Descriptive information of study population

\begin{tabular}{|c|c|}
\hline Gender, $\mathbf{n}$ & 11,340 \\
\hline Female, $\mathrm{n}(\%)$ & $6137(54.1 \%)$ \\
\hline Male, n (\%) & $5203(45.9 \%)$ \\
\hline \multicolumn{2}{|l|}{ Age, $n(\%)$} \\
\hline Mean, (SD) & $30.5(25.5)$ \\
\hline $0-5$ years & $2608(23.0 \%)$ \\
\hline $6-17$ years & $1949(17.2 \%)$ \\
\hline $18-65$ years & $5317(46.9 \%)$ \\
\hline $66+$ years & $1466(12.9 \%)$ \\
\hline \multicolumn{2}{|l|}{ DOW, n (\%) } \\
\hline 1 & $1073(9.5 \%)$ \\
\hline 2 & $2396(21.1 \%)$ \\
\hline 3 & $4088(36.1 \%)$ \\
\hline 4 & $2283(20.1 \%)$ \\
\hline 5 & $1500(13.2 \%)$ \\
\hline \multicolumn{2}{|l|}{ Reason for calling, $n(\%)$} \\
\hline Somatic illness & $6119(54.0 \%)$ \\
\hline Somatic injury & $2048(18.1 \%)$ \\
\hline Psychiatric illness & $51(0.5 \%)$ \\
\hline Other & $444(3.9 \%)$ \\
\hline Not registered & $2678(23.6 \%)$ \\
\hline \multicolumn{2}{|l|}{ Triage outcome, $n$ (\%) } \\
\hline Telephone consultation (not seen) & $5763(50.8 \%)$ \\
\hline Face-to-face consultation & $5575(49.2 \%)$ \\
\hline Admitted to hospital ${ }^{b}$ & $581(5.2 \%)$ \\
\hline Missing & 2 \\
\hline 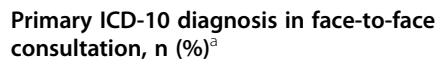 & 5575 \\
\hline Injury or external cause of morbidity & $1749(31.4 \%)$ \\
\hline $\begin{array}{l}\text { Unclear symptoms and other factors } \\
\text { influencing health status }\end{array}$ & $1055(18.9 \%)$ \\
\hline Respiratory & $979(17.6 \%)$ \\
\hline Infections & $460(8.3 \%)$ \\
\hline Eye and ear & $307(5.5 \%)$ \\
\hline Urogenital & $242(4.3 \%)$ \\
\hline Digestive & $205(3.7 \%)$ \\
\hline Musculoskeletal & $180(3.2 \%)$ \\
\hline Skin & $135(2.4 \%)$ \\
\hline Circulatory & $122(2.2 \%)$ \\
\hline Psychiatric illness & $28(0.5 \%)$ \\
\hline Other & $113(2.0 \%)$ \\
\hline Missing & 2 \\
\hline \multicolumn{2}{|l|}{ Comorbidity score, $\mathrm{n}(\%)$} \\
\hline 0 & $9202(81.2 \%)$ \\
\hline 1 & $1133(10.0 \%)$ \\
\hline $2+$ & 1005 (8.9\%) \\
\hline
\end{tabular}

${ }^{2}$ Other: nervous system, pregnancy and birth, perinatal illness, malformation and anomalies, neoplasm, blood and blood forming organs, endocrine diseases ${ }^{\mathrm{b}}$ Hospital admission is defined as having occupied a hospital bed $\geq 24 \mathrm{~h}$. This variable is calculated by subtracting the in-date-and time from out-date-and time
Maximum DOW $(\mathrm{DOW}=5)$ had a crude OR for being admitted to the hospital of 6.1 (95\%CI 3.9 to 9.6) compared to those with minimum DOW (Table 2). Callers with $\mathrm{DOW}=4$ had an OR of 4.7 (95\%CI 3.0 to 7.3), DOW $=3$ an OR of 1.8 (95\%CI 1.1 to 2.8$)$, and DOW $=2$ an OR of 0.8 (95\%CI 0.4 to 1.3). Adjusting for age and gender, callers with a DOW $=5$ had an OR of 4.0 (95\%CI 2.5 to 6.3$)$, DOW $=4$ had an OR 3.7 (95\%CI 2.4 to 5.8$), \mathrm{DOW}=3$ OR 1.7 (95\%CI 1.1 to 2.6$)$, $\mathrm{DOW}=2$ OR 0.8 (95\%CI 0.5 to 1.4 ) When adjusting for age, gender, co-morbidity, reason for contact, and caller status, the estimates changed slightly compared to the age and gender adjusted model, DOW = 5 OR 3.1 (95\% CI 2.0 to 5.0), $\mathrm{DOW}=4$ OR 3.2 (95\% CI 2.0 to 5.0$)$, $\mathrm{DOW}=3$ OR $1.6(95 \%$ CI 1.0 to 2.6$), \mathrm{DOW}=2$ OR 0.8 (95\% CI 0.5 to 1.4) compared to DOW $=1$.

\section{Sensitivity and non-response analyses}

The sensitivity analysis of using the last calls instead of the first calls barely changed the estimates.

Non-response bias analysis showed that there was no difference between all callers and the study population for age, gender and triage response (Appendix).

\section{Discussion}

\section{Main findings}

This study tested the hypothesis that callers' subjective feeling of illness severity measured as DOW was associated with hospital admission within $48 \mathrm{~h}$ after a call to a medical helpline. We found a strong doseresponse association between callers' DOW and hospital admission adjusted for age, gender, co-morbidity, reason for calling and caller status where callers with a maximum DOW had three-fold increased odds of hospital admission compared to those with a minimum DOW.

\section{Strengths and limitations}

The study benefits from the longitudinal design with complete follow-up in the high quality Danish registers. Convergent validity of the scale was seen in the dose-response of DOW and association with hospital admission [31]. A major strength of the study was the electronic setup where recall bias was bypassed; however, there might still be response (e.g. malingering) and construct bias. Malingering could have affected the results towards a higher DOW but less hospital admission, which would decrease the strength of the association. One important limitation of the present study was the fact that 25,584 (66\%) callers refused to participate, which could introduce selection bias [32]. An assessment of nonrespondents showed that non-respondents were similar to participants with regard to age, gender and 
triage response, but selection bias cannot be ruled out. Yet, very worried callers might not have wished to participate, however this fraction is supposedly limited as only a small low number of callers $(<4 \%)$ used an emergency access button to bypass the telephone waiting line in a similar study [33]. Moreover, potential severe illnesses which were treated or refuted in less than $24 \mathrm{~h}$ were not included in the endpoint, which might have drawn the results in the direction of an underestimation of the association between DOW and hospital admission. It has been discussed whether hospital admission is a good proxy for true illness severity and while no single outcome captures this concept it is suggested to use the methodology of diagnostic research where the outcome is dichotomized into the presence of illness yes/no [34]. We could have included endpoints such as: radiology, various treatments (e.g. inhalation, ECG), and prescriptions, however these endpoints could introduce bias in relation to differences in frequency in illness/ injuries. Therefore, we chose to use hospital admission defined as hospital stay $\geq 24 \mathrm{~h}$ as the proxy for illness severity. In a large register study on the scope of the $\mathrm{OOH}$ from Denmark ( $n=7810$ contacts) the researchers found that $n=102(1.3 \%)$ were calls regarding chest pain and $29.4 \%$ of these were admitted directly to hospital [35]. These and other potential severe illnesses might have been discharged within $24 \mathrm{~h}$ and might therefore not contribute to the outcome measure of hospitalization $\geq 24 \mathrm{~h}$. This study did not address the predictive value (sensitivity and specificity) of DOW as the study design did not allow this analysis. Therefore, we cannot conclude that DOW is suited to increase precision in telephone triage. Lastly, we did not detect a significant difference between levels of DOW and odds for hospitalization, however a dose-response trend was present, although the estimates might suffer from a lack of power or callers' discriminative ability, especially between DOW levels 4 and 5 . We used the same study population in the present study and the RCT investigating the effect of DOW on triage response. In the RCT, we tested if call handlers' awareness of DOW affected the triage response. We did not detect a difference in triage response in the RCT. Moreover, a qualitative investigation showed that the addition of DOW was to a large extent "missed" by call handlers due to several structural issues [26]. Therefore, we do not suspect the results of this study to be affected by the intervention.

\section{Comparison with the literature}

The results from this study show that the measure of the subjective feeling of worry in telephone triage provides an indication of risk of hospital admission. Studies regarding the common-sense model and selfrated health can be used to understand how and why self-evaluation of a condition predicts health outcomes. Self-rated health is an independent predictor of 5-year mortality, people rating their health to be bad compared to good have 1.5 to 3.0 higher odds for mortality $[19,20]$. Self-rated health is an inclusive, usually five-point rating, that is thought to provide individual but contextual relevant information on bodily conditions, sensations, emotions and feelings [22, 23]. However, whereas self-rated health predicts acute hospital admission due to chronic illness, this association has not been found in acute illness/injury [36, 37].

Table 2 Odds ratio for hospital admission (OR, 95\% Cl, forest plot)

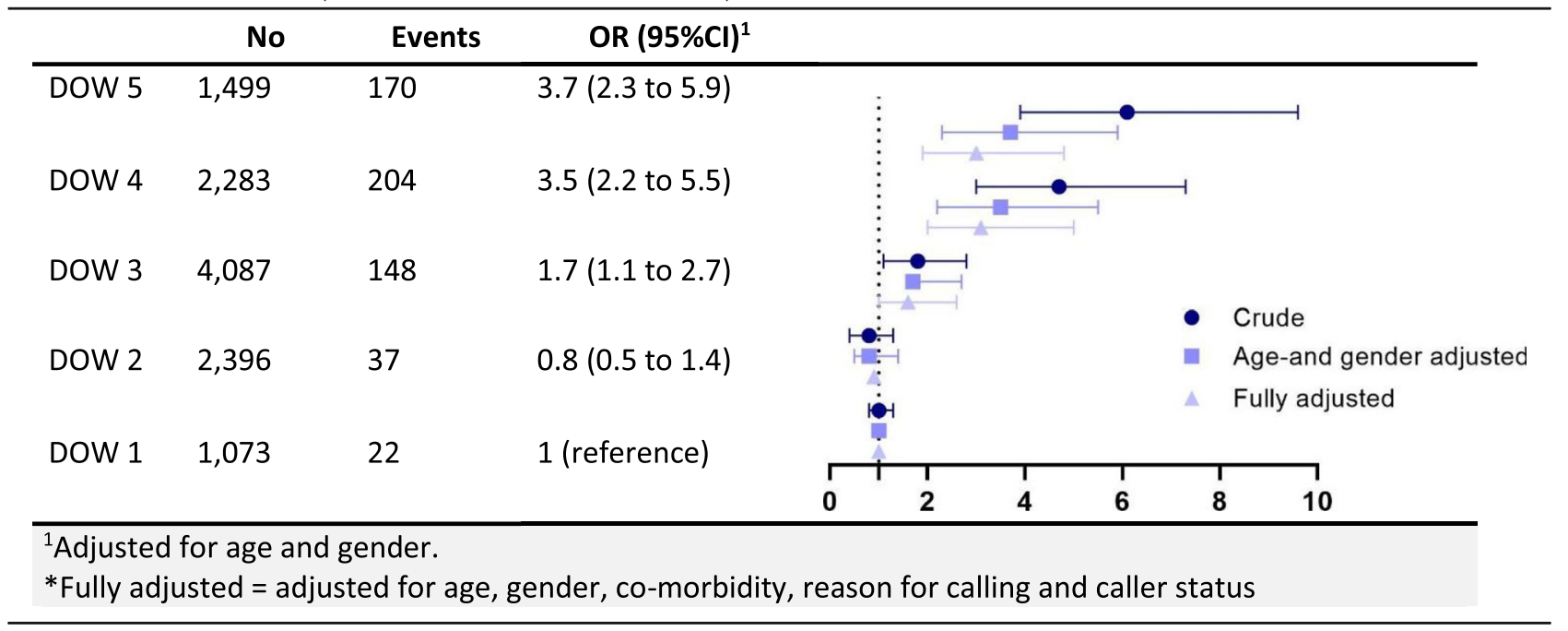


We suggest that DOW might be associated with selfassessed illness severity in the short time span, while self-rated health evaluates chronicity and predicts mortality in the longer run.

In a meta-analysis of The Brief Illness Perception Questionnaire, which is a questionnaire based on the common sense model, the results indicate that higher concern (emotional response) predicts worse outcome in illness [14]. In this study, risk of hospital admission is strongly associated with the level of DOW. However, strong illness identity has been shown to be positively associated with emotional coping strategies [24], and one could argue that patients who openly show their worry are more inclined to receive treatment/hospital admission. There is a relation between the conceptual theory behind the common-sense model and DOW. Secondary analysis of data from a feasibility study on DOW found that the caller with a strong illness identity, short illness duration, a clear cause and solution for cure and control were more likely to present a low DOW [38]. In the current study, we present a strong association between DOW and hospital admission and thus established the connection between illness representation, DOW and outcome.

Implementation of DOW in telephone triage could benefit as an addition to the existing criterion-based triage tools in clinical decision-making by introducing early patient participation in emergency care [39-41]. Traditionally, emergency medicine has been dominated by the acute-care paradigm, where the power asymmetry between provider and patient is evident [42, 43]. There is a general sparsity of studies on patient participation in acute and emergency medicine setting [44]. The implementation of DOW could initiate patient centeredness and patient participation, and in doing so take a step in the direction of a paradigm shift in acute and emergency care. One of the few studies on patient participation in emergency care hypothesized that patients' autonomy in decision-making was inversely associated to higher level of urgency. The prospective study found that patients indeed wished to be involved in decision-making regardless of level of acuity ( $p=$ 0.41) [45]. The emotional feeling of worry is a catalyst for help-seeking, however, this is rarely touched upon in telephone triage $[17,46]$. A Danish study of 200 audio-recorded telephone triage conversations found that callers were invited to express their emotional state in less than $2 \%$ of the calls [10]. In an analysis of malpractice claim cases the authors found that a failure to respond to the callers' concern, closed biomedical questions and less information sharing characterized malpractice claims in cases compared to matched controls [15, 16, 47]. In a feasibility study on DOW we found that the question of "how worried are you about the situation, you're calling in about on a scale from 1 to 5 " probed more medical information sharing, and could facilitate an investigation into the callers worry with e.g.: "you say you score four in worry, why is that?" [18]. The strength of this scale lies in the simplicity and a systematic implementation of DOW in triage could increase patient-centered communication and emphasize the focus on the patient's psychosocial resources in acute illness/injury, by simply asking the question of DOW and asking why DOW was rated to the specific number. The implementation of DOW in triage could also serve as a tool in the clinical decision-making process. It has been shown that the stressful environment of telephone helplines causes increased conservative triage response [48], therefore the integration of DOW in triage might also benefit resource allocation by creating a mental decoupling within the health professional [41]. Whether DOW could be used to triage the patients to higher or lower urgency remains to be evaluated.

\section{Recommendations for future practice}

The findings in this study are most likely not limited to medical helpline telephone consultation but could be applied to all health care settings with an acute patient influx that uses telephone triage. The impact of introducing DOW in triage should be evaluated by the stake holders (callers and call handlers), and an assessment of the effect on patient involvement and patient outcome and safety would be required. Barriers for implementing DOW should be explored as well as the effect on triage in both telephone triage as well as in physical triage. Moreover, studies with less strict endpoints like e.g. prescriptions, shorter hospital stay, and treatments could further validate the findings of this study.

\section{Conclusion}

Callers' subjective feeling of illness severity measured as DOW was strongly associated with hospital admission within $48 \mathrm{~h}$ after contacting a medical helpline. A high DOW was associated with higher odds for hospital admission by six-fold in crude analysis and by three -fold in the age, gender, co-morbidity, reason for contact, and caller status adjusted analysis. DOW could be included in the existing clinical decision tools and support clinical decision making by telephone. An integration of the DOW scale in acute health care telephone consultations might help the callers to express their feelings and emotions motivating their contact to an acute care telephone helpline. 


\section{Appendix}

Table $\mathbf{3}$ Descriptive of the full population with a valid personal identification number in the data collection period compared to the study population

\begin{tabular}{|c|c|c|}
\hline & $\begin{array}{l}\text { All calls, } \\
n=38,787 \\
(100 \%)\end{array}$ & $\begin{array}{l}\text { Study population, } \\
n=11,340(33 \%)\end{array}$ \\
\hline \multicolumn{3}{|l|}{ Gender, n (\%) } \\
\hline Female & $21,248(54.8 \%)$ & $6137(54.1 \%)$ \\
\hline Male & $17,538(45.22 \%)$ & $5203(45.9 \%)$ \\
\hline \multicolumn{3}{|l|}{ Age, $n(\%)$} \\
\hline $0-5$ years & $8994(23.2 \%)$ & $2608(23.0 \%)$ \\
\hline $6-18$ years & $6236(16.7 \%)$ & $1949(17.2 \%)$ \\
\hline 19-65 years & $19,270(49.7 \%)$ & $5317(46.9 \%)$ \\
\hline $66+$ years & $4287(11.1 \%)$ & 1466 (12.9\%) \\
\hline \multicolumn{3}{|l|}{ Dow, n (\%) } \\
\hline 1 & N/A & $1073(9.5 \%)$ \\
\hline 2 & & $2396(21.1 \%)$ \\
\hline 3 & & $4088(36.1 \%)$ \\
\hline 4 & & $2283(20.1 \%)$ \\
\hline 5 & & $1500(13.2 \%)$ \\
\hline \multicolumn{3}{|l|}{ Self-rated health, $\mathrm{n}(\%)$} \\
\hline 1 , very good & N/A & $2120(18.9 \%)$ \\
\hline 2, good & & $2750(24.5 \%)$ \\
\hline 3, fair & & $2462(21.9 \%)$ \\
\hline 4, bad & & $2222(19.8 \%)$ \\
\hline 5 , very bad & & $1680(15.0 \%)$ \\
\hline Missing & & 106 \\
\hline \multicolumn{3}{|l|}{ Reason for calling, $\mathrm{n}(\%)$} \\
\hline Somatic illness & $20,726(53.4 \%)$ & $6119(54.0 \%)$ \\
\hline Somatic injury & $6554(16.9 \%)$ & $2048(18.1 \%)$ \\
\hline Psychiatric illness & $217(0.6 \%)$ & $51(0.5 \%)$ \\
\hline Other & $2017(5.2 \%)$ & $444(3.9 \%)$ \\
\hline Missing & $9273(23.9 \%)$ & $2678(23.6 \%)$ \\
\hline \multicolumn{3}{|l|}{ Triage response, $\mathrm{n}(\%)$} \\
\hline Telephone consultation & $16,980(43.8 \%)$ & $4993(44 \%)$ \\
\hline Face-to-face consultation & $18,781(48.4 \%)$ & $5649(50 \%)$ \\
\hline Other ${ }^{a}$ & $3026(7.8 \%)$ & $771(7 \%)$ \\
\hline Missing & 0 & 0 \\
\hline
\end{tabular}

a triage response "other" e.g. other guidance, answer on blood test, case summary after home visit, request for prescription

\section{Abbreviations}

MH1813: Medical helpline 1813; PIN: Personal Identification Number

\section{Acknowledgements}

The authors wish to extend their sincere gratitude to LOGIS solutions for providing the software template and to TDC Netdesign for constructing the electronic solution for the data collection. Moreover, we wish to thank Jens
Morten Haugård and Stig Nikolaj Fasmer Blomberg for their assistance in setting up the data collection and aid with data management.

\section{Authors' contributions}

All authors were responsible for the study concept and design. HGJ and FL were responsible for the acquisition of data and HGJ and LT conducted the analysis of data. All authors contributed to the interpretation of the data. HGJ drafted the manuscript. All authors critically revised the manuscript for important intellectual content and approved the final version. The corresponding author attests that all listed authors meet authorship criteria and that no others meeting the criteria have been omitted. HGJ is the guarantor. The author(s) read and approved the final manuscript.

\section{Funding}

This study was founded by The Danish foundation TrygFonden, an unrestricted grant from the Laerdal Foundation and the Danish Nurses' Association. The founding sources had no influence in the study design, data collection, analysis or interpretation of data.

\section{Ethics approval and consent to participate}

All participants gave informed consent. The study was approved by the National Board of Health, reference number 3-3013-1416/1/ and the National Data Protection Agency PVH-2015-004, I-Suite number: 04330. The National Ethics Committee was consulted, and approval was not deemed necessary H-15016323.

\section{Consent for publication}

Not applicable.

\section{Competing interests}

The authors declare that they have no competing interests.

\section{Author details}

'Emergency Medical Services Copenhagen, Copenhagen University, Copenhagen, Denmark. ${ }^{2}$ Clinical Research Centre, Amager and Hvidovre Hospital, University of Copenhagen, Copenhagen, Denmark. ${ }^{3}$ Clinic of Internal and Emergency Medicine and Department of Anesthesiology and Intensive Care, Aalborg University Hospital, Aalborg, Denmark. ${ }^{4}$ Center for Prehospital and Emergency Research, Department of Clinical Medicine, Aalborg University, Aalborg, Denmark. ${ }^{5}$ Department of Cardiology, Gentofte Hospital, University of Copenhagen University Hospital, Copenhagen, Denmark. ${ }^{6}$ Department of Intensive Care, Rigshospitalet, University of Copenhagen, Copenhagen, Denmark. ${ }^{7}$ Research Unit for General Practice, Aarhus, Denmark. ${ }^{8}$ Department of Emergency Medicine, Odense University Hospital, Odense, Denmark. ${ }^{9}$ Department of Emergency Medicine, Hospital of South West Jutland, Esbjerg, Denmark. ${ }^{10}$ National Institute of Public Health, University of Southern Denmark, Copenhagen, Denmark.

Received: 26 December 2019 Accepted: 26 May 2020

Published online: 10 June 2020

\section{References}

1. Pedersen KM, Andersen JS, Sondergaard J. General practice and primary health Care in Denmark. J Am Board Fam Med. 2012;25(Suppl 1):S34-8.

2. Huibers L, Moth $G$, Carlsen AH, Christensen MB, Vedsted P. Telephone triage by GPs in out-of-hours primary care in Denmark: a prospective observational study of efficiency and relevance. Br J Gen Pract. 2016;66(650): e667-73.

3. Leprohon J, Patel VL. Decision-making strategies for telephone triage in emergency medical services. Med Decis Mak. 1995;15:240-53.

4. Gamst-Jensen H, Lippert F, Egerod I. Under-triage in telephone consultation is related to non-normative symptom description and interpersonal communication: a mixed methods study. Scand J Trauma Resusc Emerg Med. 2017:25(1):52.

5. Moth G, Flarup L, Christensen MB, Olesen F, Vedsted P. Kontakt- og sygdomsmønsteret i lægevagten LV-KOS 2011 [Contact-and disease pattern in the Out-of-Hours services]. 2011. Available from: http://www.laeger.dk/ nyhed/download/docs/F7173/Kontakt-og sygdomsmønsteret i lægevagten LV-KOS 2011.pdf. 
6. van lerland $Y$, van Veen $M$, Huibers L, Giesen $P$, Moll HA. Validity of telephone and physical triage in emergency care: the Netherlands triage system. Fam Pract. 2011;28(3):334-41.

7. Zachariasse JM, Seiger N, Rood PPM, Alves CF, Freitas P, Smit FJ, et al. Validity of the Manchester triage system in emergency care: a prospective observational study. PLoS One. 2017;12(2):1-14.

8. Steiner D, Renetseder F, Kutz A, Haubitz S, Faessler L, Anderson JB, et al. Performance of the Manchester triage system in adult medical emergency patients: a prospective cohort study. J Emerg Med. 2015;50(4):678-89.

9. Purc-Stephenson RJ, Thrasher C. Nurses' experiences with telephone triage and advice: a meta-ethnography. J Adv Nurs. 2010;66:482-94.

10. Vilstrup E, Graversen DS, Huibers L, Christensen MB, Pedersen AF. Communicative characteristics of general practitioner-led and nurse-led telephone triage at two Danish out-of- hours services : an observational study of 200 recorded calls. BMJ Open. 2019:1-8.

11. Leventhal H, Nerenz DR, Steele DJ. Illness repesentations and coping with health threats. In: Handbook of psychology and health. Hillsdale: Lawrence Erlbaum Associates; 1984. p. 189-215.

12. Diefenbach MA, Miller SM, Porter M, Peters E, Stefanek M, Leventhal H. Emotions and health behavior: A self-regulation perspective. In: Handbook of emotions. 3rd ed. New York: Guilford Press; 2008. p. 645-60.

13. Broadbent E, Petrie KJ, Main J, Weinman J. The brief illness perception questionnaire. J Psychosom Res. 2006;60(6):631-7.

14. Broadbent E, Wilkes C, Koschwanez H, Weinman J, Norton S, Petrie KJ. A systematic review and meta-analysis of the brief illness perception questionnaire. Psychol Health. 2015;30(11):1361-85.

15. Ernesäter A, Winblad U, Engström M, Holmström IK. Malpractice claims regarding calls to Swedish telephone advice nursing: what went wrong and why? J Telemed Telecare. 2012;18(7):379-83.

16. Ernesäter A, Engström M, Winblad U, Holmström IK. A comparison of calls subjected to a malpractice claim versus "normal calls" within the Swedish Healthcare Direct: A case-control study. BMJ Open. 2014;4(10):1-7.

17. Keizer E, Smits M, Peters Y, Huibers L, Giesen P, Wensing M. Contacts with out-of-hours primary care for nonurgent problems: patients' beliefs or deficiencies in healthcare? BMC Fam Pract. 2015;16(1):157.

18. Gamst-Jensen H, Huibers L, Pedersen K, Christensen EFEF, Ersbø\|ll AK, Lippert $\mathrm{FK}$, et al. Self-rated worry in acute care telephone triage: a mixed-methods study. Br J Gen Pract. 2018;68(668):bjgp18X695021.

19. Desalvo KB, Blaser N, Reynolds K. Mortality prediction with a single general self-rated health question - a meta-analysis. Prev Chronic Dis. 2010;7(1):267-75.

20. Idler EL, Benyamini Y. Self-rated health and mortality : a review of twentyseven community studies. J Health Soc Behav. 1997:38(1):21-37.

21. Benyamini Y, Idler EL. Community studies reporting association between self-rated health and mortality: additional studies, 1995 to 1998. Res Aging. 1999;21(3):392-401.

22. Jylha M. Social Science \& Medicine What is self-rated health and why does it predict mortality ? Towards a unified conceptual model. Soc Sci Med. 2009;69:307-16.

23. Idler EL, Hudson SV, Leventhal $H$. The meanings of self-ratings of health: a qualitative and quantitative approach. Res Aging. 1999;21(3):458-76.

24. Thygesen LC, Daasnes C, Thaulow I, Brønnum-Hansen H. Introduction to Danish (nationwide) registers on health and social issues: structure, access, legislation, and archiving. Scand J Public Health. 2011;39(7):12-6.

25. Statistics Denmark. Statistikbanken. [cited 2018 Aug 1]. Available from: http://www.statistikbanken.dk/statbank5a/default.asp?w=1920.

26. Gamst-Jensen H, Frishknecht Christensen E, Lippert F, Folke F, Egerod I, Brabrand $M$, et al. Impact of caller's degree-of-worry on triage response in out-of-hours telephone consultations: a randomized controlled trial. Scand J Trauma Resusc Emerg Med. 2019;27(1):1-7.

27. Pedersen CB. The Danish Civil Registration System. Scand J Public Health. 2011;39(7_suppl):22-5.

28. Lynge E, Sandegaard $J$, Rebolj M. The Danish National Patient Register. Scand J Public Health. 2011:39:30-3.

29. Thygesen SK, Christiansen CF, Christensen S, Lash TL, Sørensen HT. The predictive value of ICD-10 diagnostic coding used to assess Charlson comorbidity index conditions in the population-based Danish National Registry of patients. BMC Med Res Methodol. 2011;11(1):83.

30. Charlson ME, Pompei P, Ales KL, MacKenzie RC. A new method of classifying prognostic in longitudinal studies: development and validation. J chron dis. 1987:40(5):373-83.
31. Willert CB, Hölmich LR, Thorborg K. Udvikling og validering af patientrapporterede spørgeskemaer - del 1. [Development and validation of patient-reported questionnaires - part 1]. Ugeskrift for læger. 2015;1-4.

32. Baruch $Y$, Holtom BC. Survey response rate levels and trends in organizational research. Hum Relations. 2008;61(8):1139-60.

33. Ebert JF, Huibers L, Christensen B, Lippert FK, Christensen MB. Giving callers the option to bypass the telephone waiting line in out-of-hours services: a comparative intervention study. Scand J Prim Health Care. 2019;37(1):120-7.

34. Moll HA. Challenges in the validation of triage systems at emergency departments. J Clin Epidemiol. 2010;63(4):384-8.

35. Moth $G$, Huibers L, Christensen MB, Vedsted P. Out-of-hours primary care: a population-based study of the diagnostic scope of telephone contacts. Fam Pract. 2016;33(5):504-9.

36. Farkas J, Kosnik M, Flezar M, Suskovic S, Lainscak M. Self-rated health predicts acute exacerbations and hospitalizations in patients with COPD. Chest. 2010;138(2):323-30.

37. Goldstein MS, Siegel JM, Boyer R. Predicting changes in perceived health status. Am J Public Health. 1984;74(6):611-4.

38. Thilsted SL, Egerod I, Lippert FK. Relation between illness representation and self-reported degree-of-worry in patients calling out-of-hours services: a mixed-methods study in Copenhagen, Denmark. BMJ Open. 2018;8:1-7.

39. Croskerry P. Achieving quality in clinical decision making: cognitive strategies and detection of bias. Acad Emerg Med. 2002;9(11):1184-204.

40. Croskerry P, Singhal G, Mamede S. Cognitive debiasing 1: origins of bias and theory of debiasing. BMJ Qual Saf. 2013;22(SUPPL.2):58-65.

41. Croskerry P, Singhal G, Mamede S. Cognitive debiasing 2: impediments to and strategies for change. BMJ Qual Saf. 2013;22(SUPPL.2):1-8.

42. Anderson RM, Funnell MM. Patient empowerment: reflections on the challenge of fostering the adoption of a new paradigm. Patient Educ Couns. 2005;57(2):153-7.

43. Hakimnia R, Holmström IK, Carlsson M, Höglund AT. Exploring the communication between telenurse and caller-a critical discourse analysis. Int J Qual Stud Health Well-being. 2014;9:1-9.

44. Flynn D, Knoedler MA, Hess EP, Murad MH, Erwin PJ, Montori VM, et al. Engaging patients in health care decisions in the emergency department through shared decision-making: a systematic review. Acad Emerg Med. 2012;19(8):959-67.

45. Davis MA, Hoffman JR, Hsu J. Impact of patient acuity on preference for information and autonomy in decision making. Acad Emerg Med. 2012; 19(8):959-67.

46. Cornally N, Mccarthy G. Help-seeking behaviour: a concept analysis. Int J Nurs Pract. 2011;17(3):280-8.

47. Ernesäter A, Engstrømm M, Winblad U, Rahmqvist M, Holmstrøm IK. Telephone nurses' communication and response to callers' concern-a mixed methods study. Appl Nurs Res. 2016;29:116-21.

48. Allan JL, Farquharson B, Johnston DW, Jones MC, Choudhary $\mathrm{CJ}$, Johnston M. Stress in telephone helpline nurses is associated with failures of concentration, attention and memory, and with more conservative referral decisions. Br J Psychol. 2014;105(2):200-13.

\section{Publisher's Note}

Springer Nature remains neutral with regard to jurisdictional claims in published maps and institutional affiliations.

Ready to submit your research? Choose BMC and benefit from:

- fast, convenient online submission

- thorough peer review by experienced researchers in your field

- rapid publication on acceptance

- support for research data, including large and complex data types

- gold Open Access which fosters wider collaboration and increased citations

- maximum visibility for your research: over $100 \mathrm{M}$ website views per year

At BMC, research is always in progress.

Learn more biomedcentral.com/submissions 